\title{
Effects of Resisted Sprint Training on Sprint Performance in High School Baseball Players
}

\author{
Yuta Sekine $^{1, *}$, Junichi Okada ${ }^{2}$ \\ ${ }^{1}$ Faculty of Sport Science, Nippon Sport Science University, Tokyo, Japan \\ ${ }^{2}$ Faculty of Sport Sciences, Waseda University, Tokyo, Japan
}

Email address:

y-sekine@nittai.ac.jp (Y. Sekine),jun1okd@waseda.jp (J. Okada)

${ }^{*}$ Corresponding author

\section{To cite this article:}

Yuta Sekine, Junichi Okada. Effects of Resisted Sprint Training on Sprint Performance in High School Baseball Players. American Journal of Sports Science. Vol. 4, No. 5, 2016, pp. 90-97. doi: 10.11648/j.ajss.20160405.13

Received: August 4, 2016; Accepted: August 19, 2016; Published: September 7, 2016

\begin{abstract}
Resisted sprint training (RST) affects sprint speed in the acceleration phase, but there is no research regarding this for in adolescents. This study investigated the effects of RST on sprint speed and ground reaction force (GRF) in high school baseball players. Subjects were assigned to the resisted sprint group (RSG, $n=10$, loading $20 \%$ body mass), or the normal sprint group (NSG, $\mathrm{n}=9$, without loading) and trained three days per week for eight weeks. Sprint speed [0-5, 5-10, 10-15, 15-20 and 0-20 meters (m)] and GRF [peak propulsive/resultant force, (PFpro/ PFres); impulse, (I); and ratio of force applied onto the ground (RF)] measured at the right and left foot at the start, the first step of the left foot (L1st), $5 \mathrm{~m}$ and $10 \mathrm{~m}$ were assessed before and after training. In the RSG, a significant interaction was found for sprint speed at $0-5 \mathrm{~m}(\mathrm{p}=0.028)$ and increased after training $(\mathrm{p}<0.0001)$. The $15-20 \mathrm{~m}$ sprint speed increased significantly in the NSG after training $(\mathrm{p}=0.022)$. The $0-20 \mathrm{~m}$ sprint speed increased significantly in both groups after training (RSG, $p=0.001$; NSG, $p=0.041$ ). Significant interactions were found for PFpro ( $p=0.015)$ and $R F(p=0.0002)$ at the L1st in the RSG. PFpro $(p=0.005)$, PFres $(p=0.038)$ and $R F(p=0.0002)$ at L1st increased significantly in the RSG. RST increased sprint speed in the early part of the acceleration phase by improving force production but prevented the improvement of sprint speed over $15 \mathrm{~m}$. Combining RST and sprint training without loading improved sprint speed in the acceleration phase.
\end{abstract}

Keywords: Acceleration, Ground Reaction Force, Speed, Adolescence

\section{Introduction}

Sprinting is an essential component of baseball and is the only physical factor used for both offense and defense [1, 2]. A faster baseball team should have a distinct advantage over the opponent during both attack and fielding [3]. The batsman and runner rarely run in a straight line greater than $27.431 \mathrm{~m}$ (the distance between bases). Therefore, sprint distances in baseball are often less than $30 \mathrm{~m}$ and are considered to be similar to the initial acceleration phase $(0-10 \mathrm{~m})$ or acceleration phase $(0-30$ $\mathrm{m})$ of a $100 \mathrm{~m}$ sprint [4-6]. Sprint speed in the acceleration phase is required in many field sports, including baseball. The particular importance of speed in the first few steps of a field sports game was examined [6]. It was found that sprint speed after starting and in the acceleration phase are very important for baseball. McFarlane divided the acceleration phase into a pure acceleration (up to approximately $15 \mathrm{~m}$ ) and a transition (approximately 15-30 m) phase, and suggested methods of training for each phase specifically. In particular, sprint training with resistance-adding equipment (tire, harness, or weight vest) is one of the best methods for developing the early phase of acceleration [5].

Several studies have reported the effects of resisted sprint training to increase sprint speed in the early part of and during the acceleration phase [7-14]. The acute effects of this type of training are decreased stride length, increased trunk angle (the angle between the trunk and the vertical axis during sprint) and increased step frequency [15-17]. Adaptations of resisted sprint training that changed kinetics (i.e. ground reaction force) and kinematics (i.e. joint angle, stride length) were recognized to improve sprint speed in the early part of the acceleration phase $[7-10,12,14]$. Several previous studies on resisted sprint training focused on approximately $13 \%$ body mass loading to 
minimize loss of sprint specificity $[8,10,11,17,18]$. On the other hand, another study instead used a load based on the degree of decreasing sprint speed [9]. and $5 \%, 12.5 \%$ or $20 \%$ body mass [7]. Kawamori et al. implemented resisted sprint training using heavy and light weights for eight weeks and reported that heavy- and light- load resisted sprint training were equally effective for improving $10 \mathrm{~m}$ sprint performance [9]. Bachero-Mena and Gonzalez-Badillo reported that resisted sprint training using a load of $20 \%$ body mass improved sprint speed more effectively in the early part of the acceleration phase compared to loads of $5 \%$ and $12.5 \%$ body mass [7]. The optimal load used during RST was not clear from these studies.

Obviously, sprint speed in the early part of or during the acceleration phase improves with resisted sprint training [7-13]. Although sprint speed early into or during the acceleration phase is one essential marker of performance in high school baseball [3, 19], the effects of this training on sprint performance, and on ground reaction force (GRF), in high school baseball players remains unknown. Preceding studies of resisted sprint training reported the effects in adults, but it is unclear whether adolescents behave similarly. In addition, most previous studies focused on changes in kinematics, and there is not much specific research that has investigated whether resisted sprint training changes GRF [9], which affects sprint speed as a biomechanical variable [20-22]. Although resisted sprint training is performed frequently among Japanese high school baseball players, there is insufficient knowledge regarding what load and distance should be used. Coaches and trainers would benefit from clearer studies of the effects of resisted sprint training in high school baseball players specifically. Therefore, the purpose of this study was to investigate the effects of resisted sprint training on sprint speed and GRF in high school baseball players.

\section{Materials and Methods}

\subsection{Subjects}

Twenty-two baseball players who had joined the single high school baseball team volunteered because this study needed similar condition or practice environments of subject to evaluate the effects of training intervention. Subjects were eligible for inclusion if they performed their best sprint without illness, without pain that influenced the sprint, or without lower extremity injuries. Subjects who could not complete the training interventions (injured a lower extremity during baseball practice or in a car accident) or those who dropped out were excluded, totaling three subjects excluded; a total of three individuals were excluded. Data from the 19 individuals who remained in the study (age: $16.4 \pm 0.4$ years; height: $168.2 \pm 6.1 \mathrm{~cm}$; body mass: $60.0 \pm 8.0 \mathrm{~kg}$ ) were included. During this study, the subjects continued their normal schedule of baseball practice (six days/week) and resistance training (three days/week).

The details and safety concerns of the interventions were explained to the study individuals, their parents, and team managers, and consent was obtained from all involved because the study individuals were younger than 18 years. The study was approved by the Waseda University Human Research Ethics Committee.

\subsection{Measurements}

\subsubsection{Sprint Speed}

Prior to testing, all subjects were instructed how to perform the trials and practiced sprinting. They completed a warm-up that consisted of low intensity jogging (5 minutes), static stretching (5 minutes) and dynamic stretching (10 minutes). They also completed sprints $(4 \times 5 \mathrm{~m}, 2 \times 10 \mathrm{~m}, 1 \times 20 \mathrm{~m}$, and $1 \times 30 \mathrm{~m})$ at maximum effort. Then, rehearsals were performed twice before the actual trials. During the sprint trials, the starting posture of each subject's body was defined as approximately $90^{\circ}$ to the left of the direction of motion, which is the same position that a player would be in when starting to steal a base during a baseball game (Figure 1-a). Just after starting, the left foot pivoted and pushed off the ground and the right foot rotated externally in the proceeding direction (Figure 1-b), and then the torso rotated into the proceeding direction (Figure 1-c).

\section{$\begin{array}{llll}d & c & b & a\end{array}$}

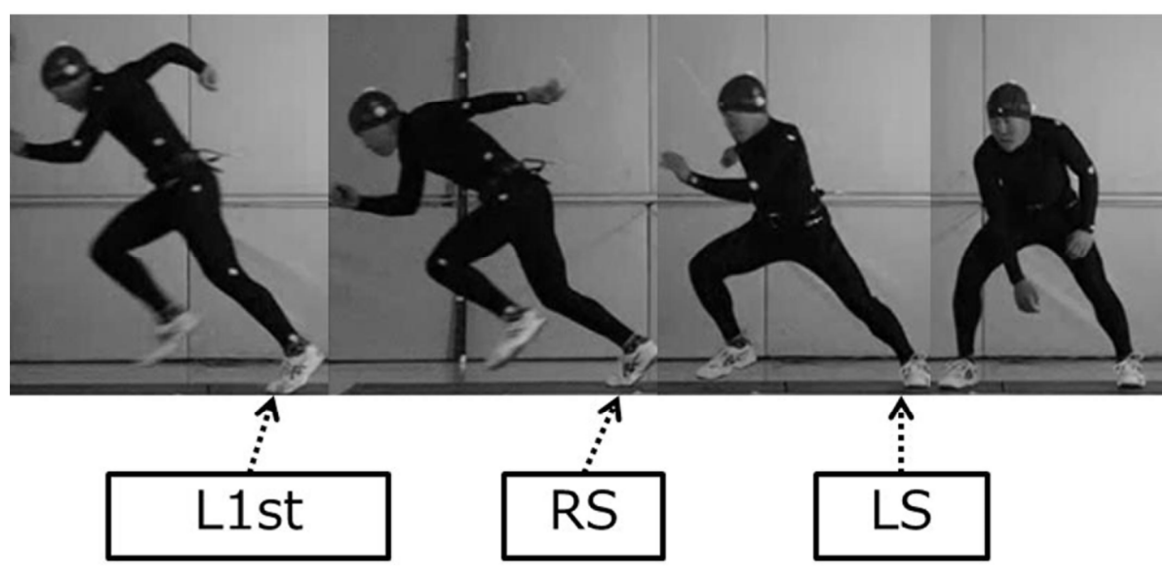

Figure 1. Starting posture. 
Sprint speeds at $0-5 \mathrm{~m}, 5-10 \mathrm{~m}, 10-15 \mathrm{~m}, 15-20 \mathrm{~m}$, and 0-20 m were measured using a velocimeter (VMS-003, VINE Corp, Tokyo, Japan). This instrument is composed of a hook, a string, a rotary encoder to detect pulses of rotation, a winding reel, and a motor running a reel. Before the trials, subjects fitted a belt $10 \mathrm{~cm}$ below the umbilicus. Pulse signals generated by a rotary encoder were sampled at 500 $\mathrm{Hz}$ and were converted into numerical values through the interface and were displayed on a screen. Based on these data, sprint speeds measured during each phase from the pulled string distance were calculated. To measure ground reaction force, Measurements were performed at a hardwood indoor basketball court which could embed the force plates. All subjects walked back to the starting line after each trial and were given two minutes rest until the next trial.

Figure captions: (a) The starting position is $90^{\circ}$ to the left of proceeding direction. (b) The left foot pushes off the ground and the right foot rotates externally. (c) The torso rotates completely into the proceeding direction and the right foot pushes off the ground. (d) Acceleration in the proceeding direction upon the first step of the left foot. Abbreviations: RS, the right foot at the start; LS, the left foot at the start; L1st, the first step of the left foot.

\subsubsection{Ground Reaction Force}

GRF at the start, $5 \mathrm{~m}$, and $10 \mathrm{~m}$ were obtained using two force plates (FP6012-15, Bertec Corp, Ohio, USA). GRF measured at the left foot at the start was defined as LS and that at the right foot at the start was defined as RS, respectively. Because GRF had to be measured at the start, 5 $\mathrm{m}$, and $10 \mathrm{~m}$, two trials were performed at each of the following start locations: a) onto the force plates; b) $5 \mathrm{~m}$ before the force plates; and c) $10 \mathrm{~m}$ before the force plates. GRFs measured at $5 \mathrm{~m}$ and $10 \mathrm{~m}$ were obtained at the first step that passed each line $(5 \mathrm{~m}$ and $10 \mathrm{~m})$, regardless of whether it was with the right or left foot. The trials were performed twice because it was not possible to collect all the data in the same session. Trials in which the foot contact was unclear were excluded and measured again after two minutes of rest. Thus, the subjects performed between two to five sprints at each start location until two successful trials could be performed completely. Horizontal force and vertical force (Fver) were measured. Among horizontal forces, a forward-countering force was defined as propulsive force (Fpro). A Vital Recorder 2 (KISSEI COMTEC, Nagano, Japan) was used to collect GRF data (sampled at $1000 \mathrm{~Hz}$ ) and data were analyzed by Kine Analyzer software (KISSEI COMTEC, Nagano, Japan). To avoid any drift, zero setting was performed just before the subjects contacted the force plates at $5 \mathrm{~m}$ or $10 \mathrm{~m}$. Resultant force (Fres) from the propulsive and vertical forces (1) were calculated and the peak values of propulsive forces (PFpro) and resultant forces (PFres) were determined. Propulsive and resultant force impulses (Ipro, Ires) were calculated from each force value and contact time (2).

$$
\begin{gathered}
\text { Fres }=\sqrt{\text { Fver }^{2}+\text { Fpro }^{2}} \\
\text { Impulse }=\int_{\text {timeA }}^{\text {timeB }} F d t
\end{gathered}
$$

Contact time at RS, L1st, $5 \mathrm{~m}$, and $10 \mathrm{~m}$ were measured as the time when Fpro and Fres increased above 10 Newton (N) and below $25 \mathrm{~N}$ [20]. At the start time, LS never left the ground and acted as a pivot to turn the body in the direction of travel. Therefore, the contact time of LS was measured from Fpro and Fres between the times when LS increased above $10 \mathrm{~N}$ after signal start and then decreased to $<25 \mathrm{~N}$. To investigate the direction of GRF, the average ratio of force applied to the ground (RF) [23] was calculated as the rate of propulsive force to the GRF (3). All GRF variables measured in each of the two included trials were averaged and used for statistical analysis.

Ratio of the force applied onto the ground $(\mathrm{RF})=$ Fpro/Fres $(3)$

\subsection{Training Protocol}

All subjects were assigned to one of two groups at random after prior measurement: the resisted sprint training group (RSG, $n=10$ ) that performed resisted sprint training and the normal sprint group (NSG, $n=9$ ) that performed sprint training without loading (Table 1). Each group performed sprint training for eight weeks (three days/week). To safely complete all training sessions, a training protocol was designed (Table 2) and all training sessions were supervised by certified strength and conditioning specialists (National Strength and Conditioning Association) and athletic trainers (Japan Sports Association). When the RSG trained, they used a universal belt (Nishi Sports, Tokyo, Japan) $10 \mathrm{~cm}$ under their navel. The belt was connected to the sled (Nishi Sports, Tokyo, Japan) by a $3 \mathrm{~m}$ joint harness (Nishi Sports, Tokyo, Japan). Bachero-Mena and Gonzalez-Badillo reported that a resisted sprint training load equaling $20 \%$ of body mass improved sprint speed in the early part of the acceleration phase [7]. Therefore, we used a training disk (UESAKA T. E., Tokyo, Japan) to set the load at approximately $20 \%$ of the subject's body mass. The NSG performed the same training without loading. In both groups, the starting posture during training was similar to that used for the sprint speed measurements before and after eight weeks of training (Figure 1). Sprint training was performed off-season because high school baseball matches were not scheduled during this time.

Table 1. Study group characteristics.

\begin{tabular}{llll}
\hline Variables & RSG $(\mathbf{n}=\mathbf{1 0})$ & NSG $(\mathbf{n}=\mathbf{9})$ & p-value \\
\hline Age $($ years $)$ & $16.5 \pm 0.5$ & $16.3 \pm 0.5$ & 0.49 \\
Height $(\mathrm{cm})$ & $167.5 \pm 4.9$ & $168.6 \pm 6.6$ & 0.70 \\
Body mass $(\mathrm{kg})$ & $60.3 \pm 6.3$ & $61.4 \pm 10.4$ & 0.78 \\
20m sprint speed $(\mathrm{m} / \mathrm{s})$ & $5.44 \pm 0.17$ & $5.57 \pm 0.16$ & 0.11 \\
\hline
\end{tabular}

RSG, resisted sprint training group; NSG, normal sprint group 
Table 2. Training program for the resisted sprint the normal sprint groups.

\begin{tabular}{|c|c|c|c|c|}
\hline Week & Interval (m) & Repetitions & Total distance/session (m) & Total distance/week (m) \\
\hline \multirow{3}{*}{1} & $0-10$ & 6 & \multirow{3}{*}{ 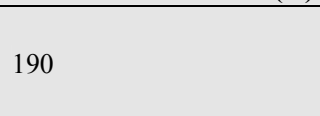 } & \multirow{3}{*}{ 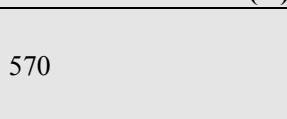 } \\
\hline & $0-15$ & 6 & & \\
\hline & $0-20$ & 2 & & \\
\hline \multirow{3}{*}{2} & $0-10$ & 8 & \multirow{3}{*}{250} & \multirow{3}{*}{750} \\
\hline & $0-15$ & 6 & & \\
\hline & $0-20$ & 4 & & \\
\hline \multirow{3}{*}{3} & $0-10$ & 8 & \multirow{3}{*}{290} & \multirow{3}{*}{870} \\
\hline & $0-15$ & 6 & & \\
\hline & $0-20$ & 6 & & \\
\hline \multirow{3}{*}{4} & $0-10$ & 8 & \multirow{3}{*}{290} & \multirow{3}{*}{870} \\
\hline & $0-15$ & 6 & & \\
\hline & $0-20$ & 6 & & \\
\hline \multirow{3}{*}{5} & $0-10$ & 6 & \multirow{3}{*}{200} & \multirow{3}{*}{600} \\
\hline & $0-20$ & 4 & & \\
\hline & $0-30$ & 2 & & \\
\hline \multirow{3}{*}{6} & $0-10$ & 8 & \multirow{3}{*}{260} & \multirow{3}{*}{780} \\
\hline & $0-20$ & 6 & & \\
\hline & $0-30$ & 2 & & \\
\hline \multirow{3}{*}{7} & $0-10$ & 8 & \multirow{3}{*}{320} & \multirow{3}{*}{1080} \\
\hline & $0-20$ & 6 & & \\
\hline & $0-30$ & 4 & & \\
\hline \multirow{3}{*}{8} & $0-10$ & 10 & \multirow{3}{*}{240} & \multirow{3}{*}{720} \\
\hline & $0-20$ & 4 & & \\
\hline & $0-30$ & 2 & & \\
\hline
\end{tabular}

\subsection{Statistical Analysis}

Before training, Student's t-tests were performed to compare the possible differences in age, height, body mass and $20 \mathrm{~m}$ sprint speed measured pretest between groups. Sprint speeds at 0-5 m, 5-10 m, 10-15 m, 15-20 m, and 0-20 m were measured before and after eight weeks of training in both groups (RSG and NSG), the absolute values were obtained, and the means and standard deviations (SD) were calculated. GRF data except for RF data were obtained per $\mathrm{N}$ of body mass and calculated as mean and SD. A two-way [group (RSG and NSG) $\times$ times (pretest and posttest)] analysis of variance (ANOVA) with repeated measures for one factor (group) was performed to consider the effects of training and performed the Bonferroni test post hoc to compare mean values when the $\mathrm{F}$ value was significant. Effect size for interaction and main effects were estimated using partial eta squared values $\left(\mathrm{p \eta}^{2}\right)$. Statistical significance was set at $\mathrm{p}<0.05$. All statistical analyses were performed using Statistical Package for the Social Sciences (version 19.0, IBM SPSS Inc., Armonk, NY, USA).

\section{Results}

\subsection{Subjects}

There were no differences in age, height, body mass, and $20 \mathrm{~m}$ sprint speed between the RSG $(n=10)$ and NSG $(n=9)$ (Table 1); therefore, the groups were divided similarly.

\subsection{Sprint Speed}

Sprint speeds measured at $0-5 \mathrm{~m}, 5-10 \mathrm{~m}, 10-15 \mathrm{~m}, 15-20$ $\mathrm{m}$, and $0-20 \mathrm{~m}$ in both groups (RSG and NSG) before and after training are presented in Table 3. A significant interaction was noted for the $0-5 \mathrm{~m}$ sprint speed $\left(\mathrm{p \eta}^{2}=0.254\right.$, $\mathrm{p}=0.028$ ), and it was significantly increased in the RSG after training $\left(\mathrm{p \eta}^{2}=0.611, \mathrm{p}<0.0001\right)$. In all, the $15-20 \mathrm{~m}$ sprint speed increased significantly in the NSG after training $\left(\mathrm{p} \eta^{2}=0.277, \mathrm{p}=0.022\right)$ and the $0-20 \mathrm{~m}$ sprint speed increased significantly in both training groups (RSG: $\mathrm{p \eta}^{2}=0.475$, $\mathrm{p}=0.001 ; \quad$ NSG: $\left.\mathrm{p}^{2}=0.223, \mathrm{p}=0.041\right)$. No significant differences were found for the $5-10 \mathrm{~m}$ and $10-15 \mathrm{~m}$ sprint speeds in both groups.

Table 3. Sprint speeds measured before (pre) and after (post) training.

\begin{tabular}{lllll}
\hline \multirow{2}{*}{$\begin{array}{l}\text { Sprint } \\
\text { phase }\end{array}$} & \multicolumn{4}{l}{ Mean \pm SD of sprint speed $(\mathrm{m} / \mathbf{s})$} \\
\cline { 2 - 5 } & RSG & \multicolumn{4}{l}{ NSG } \\
\cline { 2 - 5 } & Pre & Post & Pre & Post \\
\hline $0-5 \mathrm{~m}$ & $3.40 \pm 0.17$ & $3.60 \pm 0.15^{* * * *}$ & $3.50 \pm 0.16$ & $3.56 \pm 0.10$ \\
$5-10 \mathrm{~m}$ & $6.20 \pm 0.21$ & $6.31 \pm 0.15$ & $6.34 \pm 0.22$ & $6.40 \pm 0.34$ \\
$10-15 \mathrm{~m}$ & $6.98 \pm 0.24$ & $6.97 \pm 0.22$ & $7.11 \pm 0.29$ & $7.14 \pm 0.20$ \\
$15-20 \mathrm{~m}$ & $7.32 \pm 0.26$ & $7.37 \pm 0.20$ & $7.46 \pm 0.34$ & $7.73 \pm 0.46^{*}$ \\
$0-20 \mathrm{~m}$ & $5.44 \pm 0.18$ & $5.59 \pm 0.14^{* *}$ & $5.57 \pm 0.16$ & $5.66 \pm 0.13^{*}$ \\
\hline
\end{tabular}

RSG, resisted sprint training group; NSG, normal sprint group $\dagger \mathrm{p}<0.05$, significant difference between RSG and NSG, interaction effect. $* * * \mathrm{p}<0.001$ significant difference within the same group, main effect for the time of test (pre and post).

** $\mathrm{p}<0.01$ significant difference within the same group, main effect for the time of test (pre and post).

$* p<0.05$ significant difference within the same group, main effect for the time of test (pre and post).

\subsection{Ground Reaction Force}

Peak propulsive and resultant force (PFpro and PFres) in 
both groups (RSG and NSG) before and after training are presented in Table 4. A significant interaction was found for PFpro at the L1st $\left(\mathrm{p \eta}^{2}=0.299, \mathrm{p}=0.015\right)$. PFpro and PFres at the L1st increased significantly in the RSG after training (PFpro: $\mathrm{p}^{2}=0.378, \mathrm{p}=0.005$; PFres: $\mathrm{p \eta}^{2}=0.230, \mathrm{p}=0.038$ ). No significant differences were found for $\mathrm{PF}$ data measured at other locations in both groups.

A significant interaction was noted for the ratio of forces applied to the ground (RF) measured at L1st $\left(\mathrm{p}^{2}=0.563\right.$, $\mathrm{p}=0.0002$ ) and increased significantly in the RSG after training $\left(\mathrm{p \eta}^{2}=0.577, \mathrm{p}=0.0002\right)$ (Table 5). RF data measured at other locations did not change significantly after training in both groups. Propulsive and resultant impulses measured at all locations did not change significantly after training in both groups (Table 6).

Table 4. Peak propulsive/resultant force (PFpro and PFres) before (pre) and after (post) training.

\begin{tabular}{|c|c|c|c|c|c|}
\hline \multirow{3}{*}{ Foot positions } & \multirow{3}{*}{ Variable } & \multicolumn{4}{|c|}{ Mean \pm SD of peak propulsive and resultant forces $(\mathrm{N} / \mathrm{N})$} \\
\hline & & \multicolumn{2}{|l|}{ RSG } & \multicolumn{2}{|l|}{ NSG } \\
\hline & & Pre & Post & Pre & Post \\
\hline \multirow{2}{*}{ LS } & PFpro & $0.82 \pm 0.08$ & $0.80 \pm 0.07$ & $0.77 \pm 0.09$ & $0.74 \pm 0.06$ \\
\hline & PFres & $1.71 \pm 0.22$ & $1.78 \pm 0.18$ & $1.59 \pm 0.13$ & $1.61 \pm 0.15$ \\
\hline \multirow{2}{*}{ RS } & PFpro & $0.91 \pm 0.13$ & $0.90 \pm 0.11$ & $0.78 \pm 0.11$ & $0.82 \pm 0.11$ \\
\hline & PFres & $1.55 \pm 0.21$ & $1.62 \pm 0.22$ & $1.57 \pm 0.22$ & $1.52 \pm 0.12$ \\
\hline L1st & PFpro & $0.80 \pm 0.11$ & $0.89 \pm 0.11 \uparrow * *$ & $0.88 \pm 0.07$ & $0.87 \pm 0.07$ \\
\hline \multirow{2}{*}{$5 \mathrm{~m}$} & PFpro & $0.73 \pm 0.07$ & $0.70 \pm 0.10$ & $0.70 \pm 0.14$ & $0.69 \pm 0.06$ \\
\hline & PFres & $2.57 \pm 0.30$ & $2.31 \pm 0.42$ & $2.33 \pm 0.56$ & $2.16 \pm 0.39$ \\
\hline \multirow{2}{*}{$10 \mathrm{~m}$} & PFpro & $0.69 \pm 0.05$ & $0.67 \pm 0.06$ & $0.65 \pm 0.04$ & $0.62 \pm 0.06$ \\
\hline & PFres & $2.71 \pm 0.36$ & $2.86 \pm 0.37$ & $2.64 \pm 0.54$ & $2.67 \pm 0.39$ \\
\hline
\end{tabular}

RSG, resisted sprint training group; NSG, normal sprint group

$\dagger \mathrm{p}<0.05$ significant difference between RSG and NSG, interaction effect.

$* * \mathrm{p}<0.01$ significant difference within the same group, main effect for time of test (pre and post).

$* \mathrm{p}<0.05$ significant difference within the same group, main effect for time of test (pre and post).

N/N, Force (Newton)/Body mass (Newton); LS, the left foot at the start; RS, the right foot at the start; L1st, the first step of the left foot; $5 \mathrm{~m}$, the first step passed after the $5 \mathrm{~m}$ line; $10 \mathrm{~m}$, the first step passed after the $10 \mathrm{~m}$ line.

Table 5. Ratio of force applied to the ground $(R F)$ before (pre) and after (post) training.

\begin{tabular}{llll}
\hline \multirow{2}{*}{ Foot position } & \multicolumn{2}{l}{ Mean \pm SD of force applied to the ground (\%) } & NSG \\
\cline { 2 - 4 } & RSG & Post & Pre \\
\cline { 2 - 3 } & Pre & $42.0 \pm 3.9$ & $42.6 \pm 4.4$ \\
\hline LS & $42.4 \pm 4.4$ & $44.7 \pm 4.0$ & $44.9 \pm 5.0$ \\
RS & $45.3 \pm 3.5$ & $40.2 \pm 4.0$ Pos* $^{* *}$ & $39.1 \pm 3.8$ \\
L1st & $36.5 \pm 2.9$ & $22.2 \pm 1.6$ & $23.4 \pm 1.4$ \\
$5 \mathrm{~m}$ & $23.0 \pm 2.5$ & $17.3 \pm 1.4$ & $19.3 \pm 2.1$ \\
$10 \mathrm{~m}$ & $17.8 \pm 2.2$ & & $34.3 \pm 5.9$ \\
\hline
\end{tabular}

RSG, resisted sprint training group; NSG, normal sprint group

$\$ \mathrm{p}<0.001$ significant difference between RSG and NSG, interaction effect

*** $\mathrm{p}<0.001$ significant difference within the same group, main effect for the time of test (pre and post).

LS, the left foot at a starting; RS, the right foot at a starting; L1st, the first step of the left foot; $5 \mathrm{~m}$, the first step passed after $5 \mathrm{~m}$ line; $10 \mathrm{~m}$, the first step passed after $10 \mathrm{~m}$ line

Table 6. Propulsive/resultant force impulse (Ipro and Ires) before (pre) and after (post) training.

\begin{tabular}{|c|c|c|c|c|c|}
\hline \multirow{3}{*}{$\begin{array}{l}\text { Foot } \\
\text { position }\end{array}$} & \multirow{3}{*}{ Variable } & \multicolumn{4}{|c|}{ Mean \pm SD of propulsive and resultant force impulse $(N \cdot s / N)$} \\
\hline & & \multicolumn{2}{|l|}{ RSG } & \multicolumn{2}{|l|}{ NSG } \\
\hline & & Pre & Post & Pre & Post \\
\hline \multirow{2}{*}{ LS } & Ipro & $84.5 \pm 9.7$ & $84.0 \pm 18.6$ & $84.6 \pm 9.7$ & $80.2 \pm 16.2$ \\
\hline & Ires & $176.7 \pm 52.9$ & $184.6 \pm 49.9$ & $181.7 \pm 27.7$ & $178.7 \pm 41.4$ \\
\hline \multirow{2}{*}{ RS } & Ipro & $41.4 \pm 11.2$ & $36.3 \pm 13.3$ & $44.4 \pm 15.4$ & $44.8 \pm 13.4$ \\
\hline & Ires & $89.7 \pm 25.2$ & $78.8 \pm 27.7$ & $91.8 \pm 32.1$ & $100.8 \pm 40.1$ \\
\hline \multirow{2}{*}{ L1st } & Ipro & $18.9 \pm 3.2$ & $18.1 \pm 3.9$ & $19.7 \pm 1.9$ & $18.4 \pm 2.9$ \\
\hline & Ires & $54.9 \pm 6.8$ & $54.0 \pm 7.3$ & $46.2 \pm 9.5$ & $46.2 \pm 14.4$ \\
\hline \multirow{2}{*}{$5 \mathrm{~m}$} & Ipro & $6.1 \pm 1.5$ & $6.8 \pm 1.2$ & $6.1 \pm 1.5$ & $7.3 \pm 1.0$ \\
\hline & Ires & $33.8 \pm 7.1$ & $35.5 \pm 6.2$ & $34.9 \pm 8.2$ & $38.1 \pm 6.1$ \\
\hline \multirow{2}{*}{$10 \mathrm{~m}$} & Ipro & $3.4 \pm 0.6$ & $2.8 \pm 0.3$ & $3.7 \pm 1.3$ & $2.8 \pm 0.4$ \\
\hline & Ires & $32.1 \pm 6.2$ & $32.0 \pm 4.6$ & $35.4 \pm 4.0$ & $34.1 \pm 4.7$ \\
\hline
\end{tabular}

RSG, resisted sprint training group; NSG, normal sprint group

$\mathrm{N} \cdot \mathrm{s} / \mathrm{N}$, Force (Newton) Contact time (s)/Body mass (Newton); LS, the left foot at the start; RS, the right foot at the start; L1 st, the first step of the left foot; 5 m, the first step past the $5 \mathrm{~m}$ line; $10 \mathrm{~m}$, the first step past the $10 \mathrm{~m}$ line 


\section{Discussion}

The main finding was that resisted sprint training improved the $0-5 \mathrm{~m}$ sprint speed by $5.9 \%$. This result corresponded with the results of previous studies that included resisted sprint training [8-11]. Spinks et al. reported that $0-5 \mathrm{~m}$ sprint speed increased by $9.1 \%$ for soccer and rugby football players following resisted sprint training for eight weeks with a load of $13 \%$ body mass [11]. Lockie et al. conducted resisted sprint training for six weeks using $12.6 \%$ body mass in adult males and reported that $0-5 \mathrm{~m}$ sprint speed after training improved by approximately $7.1 \%$ compared with that before training [10]. Bachero-Mena and Gonzalez-Badillo investigated the effects of seven weeks resisted sprint training using loads of $5,12.5$, and $20 \%$ body mass and demonstrated that a load of $20 \%$ body mass showed greater improvement in $0-20 \mathrm{~m}$ and $0-30 \mathrm{~m}$ sprint time than 5 and $12.5 \%$ body mass [7]. Improvements in sprint performance under $20 \mathrm{~m}$ were not described in their study; however, we measured $20 \mathrm{~m}$ sprint speed subdivided into four intervals $(0-5 \mathrm{~m}, 5-10 \mathrm{~m}, 10-15 \mathrm{~m}$ and $15-20 \mathrm{~m})$ and elucidated that $0-5 \mathrm{~m}$ sprint speed was significantly improved but $5-10 \mathrm{~m}, 10-15 \mathrm{~m}$, and $15-20 \mathrm{~m}$ sprint speed were not significantly improved in the RSG. Therefore, in addition to improving sprint speed in the early phase of acceleration [7], a load of $20 \%$ body mass may affect sprint speed just after starting $(0-5 \mathrm{~m})$. In this study, resisted sprint training influenced sprint speed in high school baseball players but was limited to the early part of the acceleration phase only.

Nevertheless, $15-20 \mathrm{~m}$ sprint speed after training in the NSG also increased by $3.6 \%$ compared with that before training. Thus, sprint speed in acceleration in high school baseball players is improved after sprint training without loading. In adolescence, anaerobic performance increases rapidly [24]. The maximum anaerobic power measured by the Wingate anaerobic test using a friction-loaded cycle ergometer increased $121 \%$ between 12-17 years of age [24]. Kato et al. noted the correlation between $50 \mathrm{~m}$ sprint speed and maximum anaerobic power and concluded that sprint speed in 15 to 17 year olds increased significantly with growth [25]. These previous studies demonstrated that maximum anaerobic power increases rapidly with growth in adolescent males. It is possible that the improvement of 15-20 m sprint speed that we observed in the NSG was actually an increase in maximum anaerobic power because of growth, and because our subjects were male high school students ( $16 \pm 0.4$ years, range $=15-17$ years $)$. However, this study only evaluated the sprint speed and did not measure physiological maturity in this study. Further research is required to investigate the effects of sprint training on physiological development in adolescence males.

Interestingly, a significant improvement in 15-20 m sprint speed was noted in the NSG, but not in the RSG. During a sprint, stride length is considered an important factor of kinematics because sprint speed is the interaction of stride frequency and stride length $[22,26]$. Lockie et al. reported that approximately $13 \%$ body mass was better to use in resisted sprint training because of its minimal disruption to sprint kinematics (i.e., stride length, stride frequency, joint angle) [17]. Several other studies also showed an improvement in sprint kinematics after resisted sprint training, however, these were only recognized at $7.5 \mathrm{~m}$ or $8 \mathrm{~m}$ from the start line, $0-10 \mathrm{~m}$, or just after starting [9, 10]. Cronin et al. showed that stride length measured at $15 \mathrm{~m}$ in a resisted sprint, with a load of $20 \%$ body mass, decreased significantly compared with a sprint without loading [16]. Altogether, these findings showed that resisted sprint training using $20 \%$ body mass at distances more than $15 \mathrm{~m}$ may affect kinematics, and resisted sprint training hindered improvement of 15-20 m sprint speed, as noted in the NSG.

An important finding was that sprint speed at $0-20 \mathrm{~m}$ increased significantly in both groups (RSG and NSG); however, when this occurred during the sprint differed between training groups (RSG: 0-5 m; NSG: 15-20 m). West et al. conducted combined resisted sprint training and normal sprint training for six weeks and reported that changes in sprint time during the acceleration phase after training were greater in the resisted sprint training group than in the normal sprint training group, demonstrating that combining resisted sprint training with normal sprint training will improve short distance sprint speed more than normal sprint training alone [12]. Our results indicated that resisted sprint training and normal sprint training may have optimal effects in different sections of the acceleration phase, and suggest that a combination of resisted sprint training and sprint training without loading improves sprint speed in the entire acceleration phase.

The relationship between sprint speed and propulsive force (peak, impulse) measured after starting has been recognized in previous studies [20-22]. Many studies have suggested the importance of exerting propulsive forces in the acceleration phase [21, 22]. In both groups, the impulses of Fpro (Ipro) and Fres (Ires) measured at all locations (LS, RS, L1st, $5 \mathrm{~m}$, and 10 m) were not significantly different. However, peak propulsive force (PFpro) and peak resultant force (PFres) measured at L1st in the RSG increased significantly after training. When a sled is towed, the frictional force applied between the sled and the ground is maximum at the start (maximum static friction), and then decreases gradually as the sled moves and finally becomes stable (dynamic friction) [27]. In addition, inertial force is exerted on the sled when resisted sprint begins. For these reasons, it is inferred that increases in PFpro and PFres measured at L1st in the RSG were influenced by frictional force and inertial force in sled towing.

In the acceleration phase of sprinting, technical ability (how to apply force to the ground) is more important than the amount of total force produced [23]. Resisted sprint training increased RF compared to sprinting without loading [16], that is, the direction of the force produced during resisted sprint is more horizontal than the force produced in sprinting without a load. In this study, RF measured at L1st increased significantly in the RSG because of resisted sprint training with a load of $20 \%$ body mass (three days/week, for eight weeks). Similar to previous studies, GRF was exerted more 
horizontally in the RSG during resisted sprint training compared with the NSG and suggested that RF was improved significantly as the effects of resisted sprint training increased.

Remarkably, GRF changed in the RSG at the L1st; on the other hand, no significant changes were noted at other locations. Such results may be influenced by the starting posture during resisted sprint training. In this study, the starting posture was defined as each subject's body at approximately $90^{\circ}$ to the left of the direction in which he will proceed, analogous to a player starting to steal base in a baseball game (Figure 1-a). Because of this specific starting posture, subjects had to turn their bodies approximately $90^{\circ}$ to the right and face the direction in which they were going to proceed. Therefore, the LS functioned as a pivot foot and the motion of the body was directed toward the proceeding direction from the RS and the L1st. Just after starting, a maximum resistance force (inertial force and frictional force exerted on the sled) was loaded to the body during resisted sprint training. In resisted sprint training, greater force was required to accelerate compared to that required to sprint without loading. In particular, resistance force loaded to the body by the inertial force and frictional force during resisted sprint training increased at the L1st, which is the first step after turning the body toward the direction in which it is about to proceed. Therefore, the effects of resisted sprint training to GRF are limited to the L1st.

\section{Conclusions}

This study showed that resisted sprint training for eight weeks improved sprint speed in the early part of the acceleration phase $(0-5 \mathrm{~m})$ and increased GRF (peak propulsive/resultant force and the ratio of force applied onto ground at the first step of the left foot) in high school baseball players. However, the improvement in sprint speed at 15-20 m that significantly increased in the NSG was not observed in the RSG. Based on the findings of this study, we conclude that, first, resisted sprint training should be performed in the early part of the acceleration phase only. Second, sprint speed in the acceleration phase may result in greater improvement when resisted sprint training and normal sprint training are combined than when either training method alone is applied. Finally, 20\% body mass is an effective load to improve sprint performance.

\section{Acknowledgments}

The authors thank all who participated in this research.

\section{References}

[1] E. Coleman, T. L. Dupler, "Changes in running speed in game situations during a season of major league baseball." J Exerc Physiol. Vol. 7, no. 3: pp. 89-93, 2004.

[2] A. E. Coleman, L. M. Lasky, "Assessing running speed and body composition in professional baseball players." J Strength Cond Res. Vol. 6, no. 4: pp. 207-213, 1992.
[3] D. J. Szymanski, G. A. Fredrick, "Baseball (part ii): A periodized speed program." Strength Cond J. Vol. 23, no. 2: pp. 44-52, 2001.

[4] C. Delecluse, "Influence of strength training on sprint running performance. Current findings and implications for training." Sports Med. Vol. 24, no. 3: pp. 147-156, 1997.

[5] B. McFarlane, "A basic and advanced technical model for speed." Strength Cond J. Vol. 15, no.: pp. 57-61, 1993.

[6] A. J. Murphy, R. G. Lockie, A. J. Coutts, "Kinematic determinants of early acceleration in field sport athletes." $J$ Sports Sci Med. Vol. 2, no. 4: pp. 144-150, 2003.

[7] B. Bachero-Mena, J. J. Gonzalez-Badillo, "Effects of resisted sprint training on acceleration with three different loads accounting for $5,12.5$, and $20 \%$ of body mass." J Strength Cond Res. Vol. 28, no. 10: pp. 2954-2960, 2014.

[8] A. Harrison, J. H. Andrew, B. Gillian, "The effect of resisted sprint training on speed and strength performance in male rugby players." J Strength Cond Res. Vol. 23, no. 1: pp. 275-283, 2009.

[9] N. Kawamori, R. U. Newton, N. Hori, K. Nosaka, "Effects of weighted sled towing with heavy versus light load on sprint acceleration ability." J Strength Cond Res. Vol. 28, no. 10: pp. 2738-2745, 2014

[10] R. G. Lockie, A. J. Murphy, A. B. Schultz, T. J. Knight, X. A. Janse de Jonge, "The effects of different speed training protocols on sprint acceleration kinematics and muscle strength and power in field sport athletes." J Strength Cond Res. Vol. 26, no. 6: pp. 1539-1550, 2012.

[11] C. D. Spinks, A. J. Murphy, W. L. Spinks, R. G. Lockie, "The effects of resisted sprint training on acceleration performance and kinematics in soccer, rugby union, and australian football players." J Strength Cond Res. Vol. 21, no. 1: pp. 77-85, 2007.

[12] D. West, J. W. Daniel, J. C. Dan, M. B. Richard, R. B. Huw, "Effects of resisted sprint training on acceleration in professional rugby union players." J Strength Cond Res. Vol. 27, no. 4: pp. 1014-1018, 2013.

[13] A. Zafeiridis, P. Saraslanidis, V. Manou, P. Ioakimidis, "The effects of resisted sled-pulling sprint training on acceleration and maximum speed performance." J Sports Med Phys Fitness. Vol. 45, no. 3: pp. 284-290, 2005.

[14] G. Petrakos, J. B. Morin, B. Egan, "Resisted sled sprint training to improve sprint performance: A systematic review." Sports Med. Vol. 46, no. 3: pp. 381-400, 2016.

[15] P. E. Alcaraz, J. M. Palao, J. L. Elvira, N. P. Linthorne, "Effects of three types of resisted sprint training devices on the kinematics of sprinting at maximum velocity." J Strength Cond Res. Vol. 22, no. 3: pp. 890-897, 2008.

[16] J. Cronin, K. Hansen, N. Kawamori, P. McNair, "Effects of weighted vests and sled towing on sprint kinematics." Sports Biomech. Vol. 7, no. 2: pp. 160-172, 2008.

[17] R. G. Lockie, A. J. Murphy, C. D. Spinks, "Effects of resisted sled towing on sprint kinematics in field-sport athletes." $J$ Strength Cond Res. Vol. 17, no. 4: pp. 760-767, 2003.

[18] P. E. Alcaraz, J. M. Palao, J. L. Elvira, "Determining the optimal load for resisted sprint training with sled towing." $J$ Strength Cond Res. Vol. 23, no. 2: pp. 480-485, 2009. 
[19] S. Nabeya, "Statistical analysis of baseball data." J Jpn Stat Soc. Vol. 36, no. 2: pp. 91-115, 2007.

[20] J. P. Hunter, R. N. Marshall, P. J. McNair, "Relationships between ground reaction force impulse and kinematics of sprint-running acceleration." J Appl Biomech. Vol. 21, no. 1: pp. 31-43, 2005.

[21] A. Mero, "Force time characteristics and running velocity of male sprinters during the acceleration phase of sprinting." Res Q Exerc Sport. Vol. 59, no. 2: pp. 94-98, 1988.

[22] A. Mero, P. V. Komi, R. J. Gregor, "Biomechanics of sprint running. A review." Sports Med. Vol. 13, no. 6: pp. 376-392, 1992.

[23] J. B. Morin, P. Edouard, P. Samozino, "Technical ability of force application as a determinant factor of sprint performance." Med Sci Sports Exerc. Vol. 43, no. 9: pp. 1680-1688, 2011.
[24] N. Armstrong, J. R. Welsman, M. Y. Chia, "Short term power output in relation to growth and maturation." Br J Sports Med. Vol. 35, no. 2: pp. 118-124, 2001.

[25] K. Kato, T. Yamanaka, M. Miyamaru, M. Ae, "Development of running performance and maximal anaerobic power in high school boys." Jpn J Phys Educ Health Sport Sci. Vol. 37, no. 3: pp. 291-304, 1992.

[26] M. J. Harland, J. R. Steele, "Biomechanics of the sprint start." Sports Med. Vol. 23, no. 1: pp. 11-20, 1997.

[27] H. Matsukawa, "Physics of friction." J Surf Sci Soc Jpn. Vol. 24, no. 6: pp. 328-333, 2003.

[28] N. Kawamori, R. Newton, K. Nosaka, "Effects of weighted sled towing on ground reaction force during the acceleration phase of sprint running." J Sports Sci. Vol. 32, no. 12: pp. 1139-1145, 2014. 